\title{
Quantifying the Uncertainty of Land Surface Temperature Retrievals From SEVIRI/Meteosat
}

\author{
Sandra C. Freitas, Isabel F. Trigo, José M. Bioucas-Dias, Member, IEEE, and Frank-M. Göttsche
}

\begin{abstract}
Land surface temperature (LST) is estimated from thermal infrared data provided by the Spinning Enhanced Visible and Infrared Imager (SEVIRI) onboard Meteosat Second Generation (MSG), using a generalized split-window (GSW) algorithm. The uncertainty of the LST retrievals is highly dependent on the input accuracy and retrieval conditions, particularly the sensor view angle and the atmospheric water vapor content. This paper presents a quantification of the uncertainty of LST estimations, taking into account error statistics of the GSW under a globally representative collection of atmospheric profiles, and a careful characterization of the uncertainty of input data, particularly the surface emissivity and forecasts of the total water vapor content. Such analysis is the basis for LST uncertainty estimation, also distributed to users, in the form of error bars, along with the LST retrievals. Moreover, the spatial coverage of SEVIRI LST is essentially determined by the LST expected uncertainty, instead of being restricted to view zenith angles below a given threshold $\left(\mathrm{e.g.}, \mathbf{6 0}^{\circ}\right)$. Within the MSG disk, the atmosphere is often dry for clear-sky conditions where angles are large (e.g., Northern and Eastern Europe and Saudi Arabia). By considering several factors that contribute to LST inaccuracies, it is possible to increase the spatial coverage to regions such as those mentioned earlier. Retrieved values are also compared with in situ observations collected in Namibia, covering a seasonal cycle. The two data sets are in good agreement with root-mean-square differences ranging between $1{ }^{\circ} \mathrm{C}$ and $2{ }^{\circ} \mathrm{C}$, which is well below the average error estimated for the satellite retrievals.
\end{abstract}

Index Terms-Infrared measurements, satellite applications, temperature.

\section{INTRODUCTION}

$\mathbf{T}$ HE SATELLITE Application Facility on Land Surface Analysis (Land-SAF), as part of the ground segment of the European Organization for the Exploitation of Meteorological Satellites (EUMETSAT), generates, on an operational basis, land surface temperature (LST) from the Spinning Enhanced Visible and Infrared Imager (SEVIRI) onboard Meteosat Second Generation (MSG) satellites [1]. LST is an important parameter for the monitoring of surface energy budget, since it is

Manuscript received October 22, 2008; revised February 17, 2009 and June 9, 2009. First published September 15, 2009; current version published December 23, 2009.

S. C. Freitas is with the Instituto de Meteorologia, 1749-077 Lisboa, Portugal.

I. F. Trigo is with the Instituto de Meteorologia, 1749-077 Lisboa, Portugal, and also with the Instituto Dom Luiz/CGUL, 1749-016 Lisboa, Portugal (e-mail: Isabel.Trigo@meteo.pt).

J. M. Bioucas-Dias is with the Instituto de Telecomunicações, Instituto Superior Técnico, Technical University of Lisbon, 1049-001 Lisboa, Portugal.

F.-M. Göttsche is with the Institut für Meteorologie und Klimaforschung, Forschungszentrum Karlsruhe, 76021 Karlsruhe, Germany.

Color versions of one or more of the figures in this paper are available online at http://ieeexplore.ieee.org.

Digital Object Identifier 10.1109/TGRS.2009.2027697 the primary variable determining the upward thermal radiation and one of the main controllers of sensible and latent heat fluxes between the surface and the atmosphere. Thus, the reliable and long-term estimation of LST is extremely important for a wide number of applications, including, among others, the following: 1) model validation [2], [3]; 2) data assimilation [4]-[6]; 3) hydrological applications [7], [8]; and 4) climate monitoring [9]-[11]. The Land-SAF LST is processed at the full SEVIRI temporal and spatial resolution, allowing the capture of the full diurnal cycle over clear-sky regions.

LST estimations from remotely sensed data are generally obtained from one or more channels within the thermal infrared atmospheric window from 8 to $13 \mu \mathrm{m}$ [12]. Operational LST retrievals often make use of split-window algorithms (see, e.g., [13] and [14]), where LST is obtained through a semiempirical regression of top-of-atmosphere (TOA) brightness temperatures of two pseudocontiguous channels, i.e., the split-window channels. The Land-SAF LST algorithm is based on the generalized split-window (GSW) formulation initially developed for AVHRR and MODIS [14], now adapted to SEVIRI splitwindow channels. The error of LST retrievals via GSW depends on the following: 1) the uncertainty of surface emissivity; 2) the water vapor content of the atmosphere; and 3) the satellite view angle. Because the latter determines the total optical path, LST estimations are often limited to satellite zenith angles (SZAs) below $\sim 60^{\circ}$, where retrieval errors are still acceptable (see, e.g., [14], [15], and [37]). In the case of geostationary platforms, already unable to provide the global coverage of polar orbiters, such view angle restrictions pose additional limitations to the product spatial coverage. A wider retrieval area must be carefully weighted against an increasing error.

Any parameter inference is of little usefulness without an uncertainty measure. Here, we discuss the calibration of the GSW algorithm used operationally by the Land-SAF and the respective assessment of LST retrieval errors. These errors take into account the expected performance of the GSW under different atmospheric conditions, as well as the characterization of input uncertainties and their propagation to the final LST estimation.

This paper is organized as follows. The next section presents the description of the SEVIRI/MSG data used for LST estimations and the database used to calibrate the Land-SAF GSW algorithm. The details of this algorithm and of the LST estimation are given in Section III, while the propagation of input uncertainties and the total error of retrieved values are discussed in Section IV. The comparison of satellite retrievals with ground LST measurements taken at a permanent validation station in Namibia (southern Africa) is analyzed in Section V. 


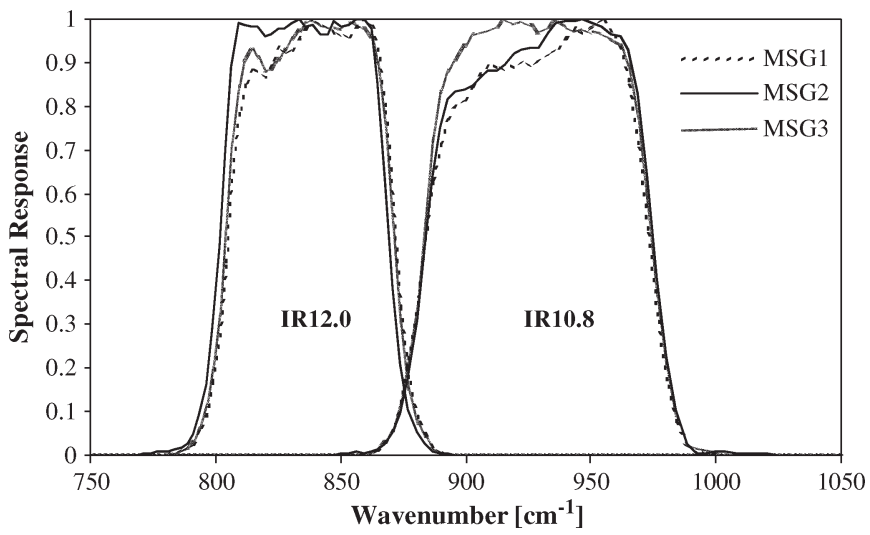

Fig. 1. Spectral response functions of SEVIRI thermal windows channels, centered at 10.8 and $12.0 \mu \mathrm{m}$, respectively, onboard MSG1, MSG2, and MSG3.

Finally, Section VI summarizes the main conclusions of this paper.

\section{DATA DESCRIPTION}

\section{A. SEVIRI Onboard MSG}

MSG is a series of four geostationary satellites to be operated by EUMETSAT. The SEVIRI is the main sensor onboard MSG, and it was designed to observe an Earth disk with view zenith angles (SZA) ranging from $0^{\circ}$ to $80^{\circ}$, with a temporal sampling of $15 \mathrm{~min}$ and a $3-\mathrm{km}$ sampling distance at the subsatellite point. SEVIRI encompasses unique spectral characteristics and accuracy, with 12 channels covering the visible to the infrared [1], [16]. The data are disseminated to users after being rectified to $0^{\circ}$ longitude, which means that the satellite viewing geometry varies slightly with the acquisition time (SZAs typically differ by less than $0.25^{\circ}$ between consecutive observations).

LST is estimated from TOA brightness temperatures of SEVIRI split-window channels, centered on 10.8 and $12.0 \mu \mathrm{m}$ (hereafter IR108 and IR120, respectively). Fig. 1 shows the response functions of these two channels for MSG1, MSG2, and MSG3 (from Meteosat- 8 onward, once operational). The expected radiometric noise for IR108 (IR120) channel available onboard MSG-1 to MSG-3 is on the order of $0.11 \mathrm{~K}$ $(0.15-0.16 \mathrm{~K})$ [16] (further details may be found at EUMETSAT Web site (http://www.eumetsat.int)). Possible inaccuracies in SEVIRI absolute or relative calibration are not considered here, despite their relevance for the quality of LST retrievals. However, it is worth mentioning that EUMETSAT has recently initiated a routine intercalibration of SEVIRI infrared channels and the Infrared Atmospheric Sounding Interferometer (IASI; onboard EUMETSAT polar-orbiter MetOp-A), with the aim of understanding the mechanisms for (changing) biases and developing operational corrections [35]. Mean differences between IASI and Meteosat-8 (Meteosat-9) reported by Hewison and Konig [35] are 0.16 and $0.13 \mathrm{~K}(0.03$ and $0.05 \mathrm{~K})$ for channels IR108 and IR120, respectively.

\section{B. Algorithm Calibration/Verification Database}

The calibration (and verification) of the GSW presented here relies on radiative transfer simulations of TOA brightness temperatures for SEVIRI channels IR108 and IR120. The simulations are performed for the database of global profiles of temperature, moisture, and ozone compiled by Borbas et al. [17] for clear-sky conditions and referred to as SeeBor. The database contains over 15700 profiles taken from other data sets, such as NOAA88 [18], TIGR-like [19], and TIGR [20], that are representative of a wide range of atmospheric (clear-sky) conditions over the whole globe. In addition, surface parameters such as skin temperatures $\left(T_{\text {skin }}\right)$ and a land-cover classification within the International Geosphere-Biosphere Program (IGBP) ecosystem categories [21] are assigned to each profile. Skin temperature over land surfaces corresponds to LST in SeeBor and is estimated as a function of 2-m temperature $\left(T_{2 m}\right)$ and solar zenith and azimuth angles [17]. In this paper, we assume that each profile corresponds to one given pixel within the Meteosat disk. Thus, for radiative simulation purposes, an SZA chosen randomly within the $0^{\circ}-80^{\circ}$ range is assigned to each profile, except for cases with the following conditions: 1) $T_{\text {skin }}$ below $270 \mathrm{~K}$, which are constrained to angles above $30^{\circ}$, and 2) $T_{\text {skin }}<240 \mathrm{~K}$, which are allowed to be observed by a geostationary satellite with a zenith angle within $60^{\circ}$ and $80^{\circ}$. This procedure ensures a realistic cover of simulated radiances for all possible viewing geometries.

The SeeBor database described earlier was split into two subsets-one used for the calibration of the LST GSW and an independent one used for verification of the fitted algorithm. The former consists of 77 atmospheres selected to cover a broad variety of water vapor content (from very dry to moist conditions), leaving more than 15600 profiles for GSW verification. The parameters in the GSW algorithm are estimated for 8 different classes of total column water vapor (TCWV) $(W)$, up to $6 \mathrm{~cm}$, and for 16 classes of SZA, up to $75^{\circ}$, ensuring that all ranges of atmospheric attenuation within the thermal infrared are covered. In order to ensure that all $W$ and SZA class have enough representative cases to provide robust parameter estimations, the radiative transfer simulations are performed over the 77 atmospheric profiles with the following settings: 1) surface temperature ranging between $T_{\text {skin }}-15 \mathrm{~K}$ and $T_{\text {skin }}+15 \mathrm{~K}$ in steps of $5 \mathrm{~K}$; 2$)$ channel emissivities of IR108 and IR120 $\left(\varepsilon_{108}\right.$ and $\varepsilon_{120}$, respectively) covering the range $0.96<\varepsilon_{120}<0.995$ in steps of 0.0175 and $\varepsilon_{120}-0.030<\varepsilon_{108}<\varepsilon_{120}+0.018$ in steps of 0.006 (excluding cases with the average of $\varepsilon_{108}$ and $\varepsilon_{120}$ below 0.94 ); and 3) SZA ranging from nadir to $75^{\circ}$ in steps of $5^{\circ}$. It is worth noting that the whole simulations cover a range of $T_{\text {skin }}$ between 230 and $341 \mathrm{~K}$ and a range of [ $T_{\text {skin }}$ minus $T_{2 m}$ ] from -20 to $+33 \mathrm{~K}$. The number of different atmospheric and surface profiles obtained by exhausting all the combinations of surface temperature, channel emissivities, and SZA is 189728 , yielding an equal number of radiative transfer simulations.

\section{Radiative Transfer Simulations}

The MODerate spectral resolution atmospheric TRANSmittance algorithm (MODTRAN4) [22] provides a useful tool to quantify the radiation emitted by the surface within known atmospheric conditions that reaches a sensor operating in a specific spectral band. The radiance $\left(L_{\nu}\right)$ is estimated using 
TABLE I

Central Wavenumber and BAND-CORRection CoEFFicients FOR SEVIRI THERMAL WINDOW CHANNELS ONBOARD MSG-1 AND MSG-2, RESPECTIVELY

\begin{tabular}{|c|c|c|c|c|c|c|}
\hline \multirow{2}{*}{ Channel } & \multicolumn{3}{|c|}{ MSG1 } & \multicolumn{3}{|c|}{ MSG2 } \\
\hline & $v_{c}\left(\mathrm{~cm}^{-1}\right)$ & $\alpha$ & $\beta(\mathrm{K})]$ & $v_{\mathrm{c}}\left(\mathrm{cm}^{-1}\right)$ & $\alpha$ & $\beta(\mathrm{K})$ \\
\hline IR108 & 930.647 & 0.9983 & 0.625 & 931.700 & 0.9983 & 0.640 \\
\hline IR120 & 839.660 & 0.9988 & 0.397 & 836.445 & 0.9988 & 0.408 \\
\hline
\end{tabular}

MODTRAN4, for the bands corresponding to IR108 and IR120 channels, with a spectral resolution of $1 \mathrm{~cm}^{-1}$. The integration of $L_{\nu}$ weighted by the $i$ th channel response function $\phi_{i, \nu}$, (see Fig. 1) provides channel $i$ effective radiance

$$
L_{i}=\frac{\int_{\nu_{i, 1}}^{\nu_{i, 2}} \phi_{i, \nu} L_{\nu} d \nu}{\int_{\nu_{i, 1}}^{\nu_{i, 2}} \phi_{i, \nu} d \nu}
$$

where $\nu_{i, 1}$ and $\nu_{i, 2}$ are the lower and upper wavenumber boundaries of the channel, respectively; the integrals in (1) are estimated by taking into account the full tabulated values of the response function $\phi_{i, \nu}$, i.e., between $\nu_{1}=781.25 \mathrm{~cm}^{-1}$ and $\nu_{2}=1136.36 \mathrm{~cm}^{-1}$, for channel IR108, and between $\nu_{1}=$ $714.28 \mathrm{~cm}^{-1}$ and $\nu_{2}=1000.00 \mathrm{~cm}^{-1}$, for channel IR 120 .

The simulated SEVIRI radiances for channel $i$, i.e., $L_{i}$ 's, are then converted to equivalent black-body brightness temperatures $\left(T b_{i}\right)$ following the analytic formulation based on the Planck function [23]

$$
T b_{i}=\left[\frac{C_{2} \nu_{i, c}}{\log \left(\frac{C_{1} \nu_{i, c}^{3}}{L_{i}}+1\right)}-\beta_{i}\right] \cdot \frac{1}{\alpha_{i}}
$$

where $\nu_{i, c}$ is channel $i$ central wavenumber (Table I), $C_{1}=$ $2 h c^{2}$, and $C_{2}=h c / k$ (with $h$ being the Planck's constant, $c$ being the speed of light, and $k$ being the Boltzmann constant). The parameters $\alpha_{i}$ and $\beta_{i}$, shown in Table I for MSG-1 and MSG-2, are band-correction coefficients, adjusted to SEVIRI ground characterization data. The simulations of IR108 and IR12.0 brightness temperatures are then performed for both MSG-1 and MSG-2, for the whole database (calibration and verification subsets) described in the previous sections.

\section{LAND-SAF LST ALGORITHM}

\section{A. GSWs}

Several algorithms have been proposed to retrieve LST from remotely sensed thermal infrared data (see, e.g., [11]-[15] and [36]-[39]). The Land-SAF LST [24] is estimated using a GSW algorithm with a formulation similar to that first proposed by Wan and Dozier [14] for AVHRR and MODIS. Thus, LST is a function of TOA brightness temperatures of SEVIRI IR108 and IR120 ( $T_{10.8}$ and $T_{12.0}$, respectively)

$$
\begin{aligned}
L S T= & \left(A_{1}+A_{2} \frac{1-\varepsilon}{\varepsilon}+A_{3} \frac{\Delta \varepsilon}{\varepsilon^{2}}\right) \frac{T_{10.8}+T_{12.0}}{2} \\
& +\left(B_{1}+B_{2} \frac{1-\varepsilon}{\varepsilon}+B_{3} \frac{\Delta \varepsilon}{\varepsilon^{2}}\right) \frac{T_{10.8}-T_{12.0}}{2} \\
& +C+\Delta L S T
\end{aligned}
$$

where $\varepsilon$ is the average of the two channels' surface emissivities; $\Delta \varepsilon$ is their difference $\left(\varepsilon_{10.8}-\varepsilon_{12.0}\right) ; A_{j}, B_{j},(j=1,2,3)$, and $C$ are the GSW coefficients obtained by fitting (3) to the calibration data described earlier; and $\triangle L S T$ is the model error. For each class of water vapor $W$ and SZA $\Psi$, a set of coefficients $A_{j}, B_{j}, C$ is inferred by minimizing the $l_{2}$-norm of the model error $\Delta L S T$. The GSW algorithm is applied to clearsky pixels only. In the Land-SAF, cloud removal is performed using the software developed by the Nowcasting (NWC) SAF, which is based on multispectral threshold technique applied to visible, near-infrared, and thermal atmospheric window channels within SEVIRI, for each pixel of the image [25].

A relevant factor in the selection of the algorithm was its expected reliability for operational LST retrievals, both in terms of expected accuracy and timeliness considering the high (15-min) generation frequency of SEVIRI LST fields. The latter favors the use of semiempirical relationships between LST and TOA brightness temperatures, which are computationally efficient and free of the convergence problems of direct emissivity and temperature retrieval methods (see, e.g., [26]) associated to the nonlinearity of the inverse problem in remote sensing (see, e.g., [27]). Recent studies have assessed the use of other window channels along with the split-window IR108 and IR120, such as the infrared bands centered on 3.9 and $8.7 \mu \mathrm{m}$ (IR39 and IR87) [28], [29]. There are, however, several caveats regarding the use of those extra channels for LST operational retrievals: 1) The uncertainty of surface emissivity within IR 39 and IR87 is considerably higher than that of channels IR108 and IR120, particularly over semiarid regions, which cover a considerably area within the Meteosat disk [30]; 2) channel IR87 has a rather low dynamic range of $300 \mathrm{~K}$, which limits its use over very warm surfaces where measurements will be close to sensor saturation; and 3) solar contamination of daytime IR39 radiances would also need to be taken into account.

The error characterization of LST retrievals is an important component of the operational algorithm and an important source of information for users. In this sense, points 1) and 2) mentioned earlier constitute the major limitation to a "fourchannel" methodology, one by increasing the retrieval error bars and the other by adding the uncertainty of the radiometer behavior close to saturation.

\section{B. Calibration/Verification of the GSW Algorithm}

The GSW parameters $A_{i}, B_{i}$, and $C$ obtained by fitting (3) to the calibration data set and the variance of LST explained by the regression are schematically shown in Fig. 2. The coefficients vary fairly smoothly throughout the $W$ and SZA classes, except 


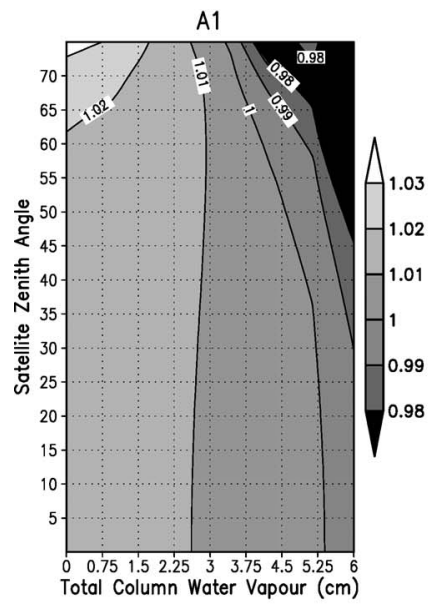

B1

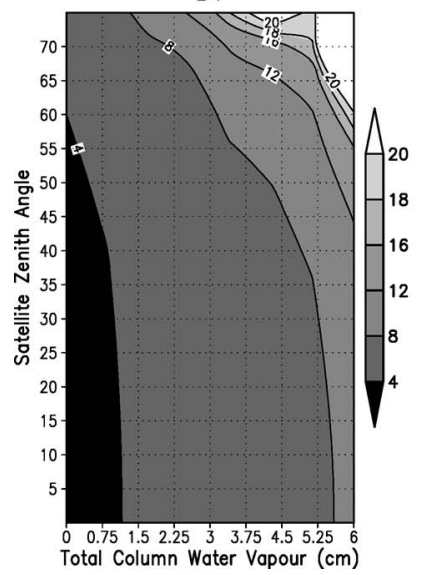

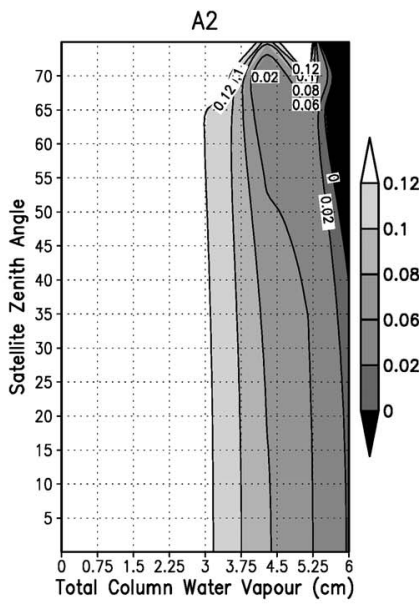

B2

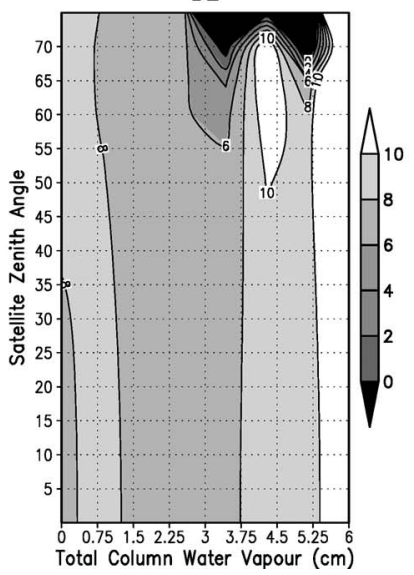

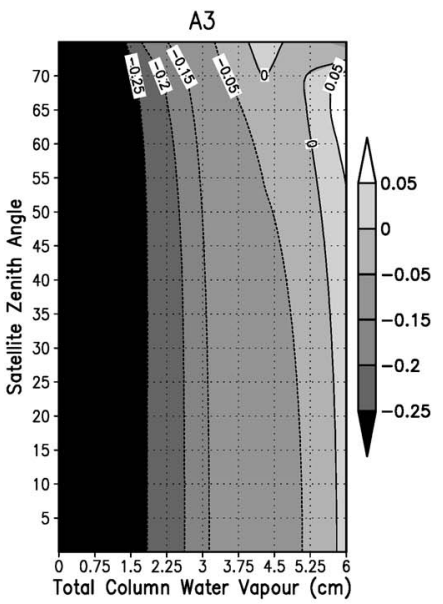

B3

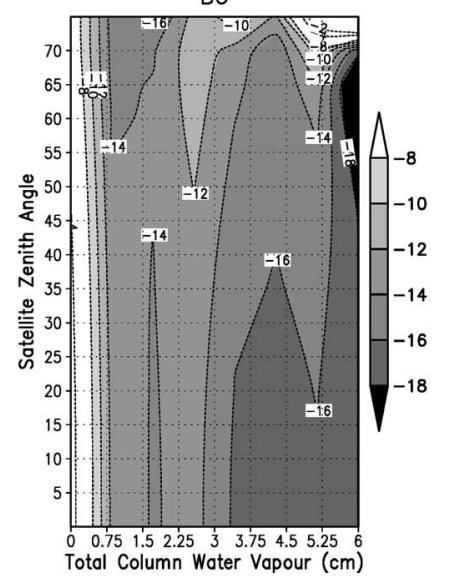

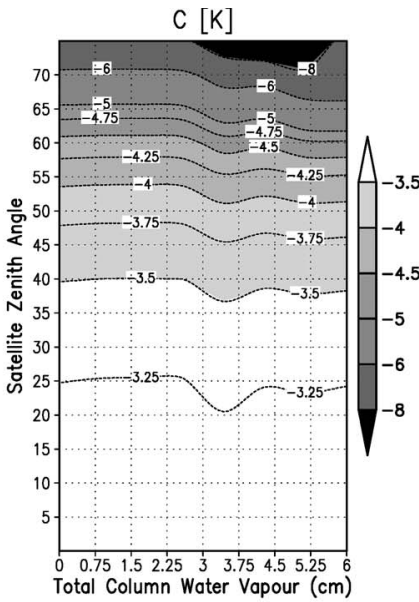

Exp Variance [\%]

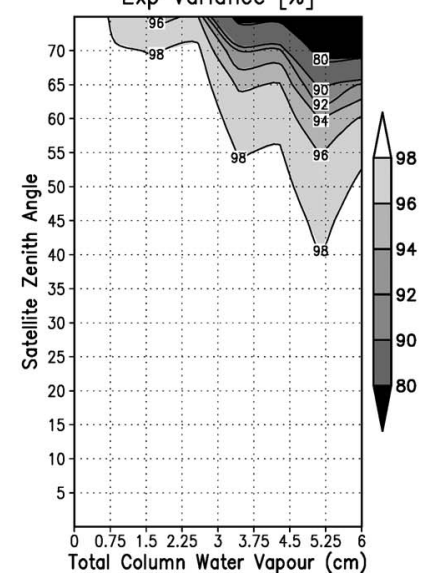

Fig. 2. Distribution of the GSW parameters (indicated at the top of each panel) and explained variance of the fitted regression (bottom left) as a function of the SZA and total column water vapor (in centimeters).

for cases where very moist atmospheres are observed with high zenith angles. In such conditions, the linear combination of the split-window channels cannot reproduce the nonlinear path length effects. As a result, the explained variance of surface temperature by TOA brightness also reaches considerably lower values (below 90\%; bottom right panel in Fig. 2), and GSW errors increase substantially.

The GSW algorithm is verified against the independent subset of simulated TOA brightness temperatures (which excludes the calibration data). Fig. 3 shows the GSW LST model error distribution within each class of $W$ and SZA. Classes with rootmean-square error (rmse) higher than $4 \mathrm{~K}$ are omitted. These classes correspond to cases where the explained variance of the GSW within the training data set is less than $93 \%$ and where errors of $10 \mathrm{~K}$ or more are commonly obtained within the verification database. Thus, we limit the operational production of LST to SZA below 67.5 when $W$ is $3 \mathrm{~cm}$ or higher, and to SZA below 62.5 when $W$ is $4.5 \mathrm{~cm}$ or higher.

The overall bias and rmse of the GSW are, respectively, 0.05 and $0.78 \mathrm{~K}$. As shown in Fig. 3, the retrieval errors tend to increase with both SZA and $W$. The rmse is always below $2 \mathrm{~K}$ for water vapor content and angles within the range of values admissible for Land-SAF LST estimations, with the exception of the following: 1) $W$ above $5.25 \mathrm{~cm}$ and SZA higher than $57.5^{\circ}$, and 2) $W$ above $2.25 \mathrm{~cm}$ and SZA higher than $72.5^{\circ}$, where the GSW presents rmse on the order of $3 \mathrm{~K}$.

\section{ERROR PROPAGATION}

In a real scenario, we do not have access to the exact GSW inputs $X=\left(T_{10.8}, T_{12.0}, \varepsilon_{10.8}, \varepsilon_{12.0}\right)$ and $Y=(W, \Psi)$, but only to inaccurate inputs, which we denote by $\hat{X}=$ $\left(\hat{T}_{10.8}, \hat{T}_{12.0}, \hat{\varepsilon}_{10.8}, \hat{\varepsilon}_{12.0}\right)$ and $\hat{Y}=(\hat{W}, \hat{\Psi})$. Therefore, if we still infer the LST according to model (3), replacing the exact GSW inputs with the inaccurate ones, we have a new source of error on the top of the fitting error $\Delta L S T$ shown in Fig. 3. In the current section, the main error sources are identified, and their impact on the total LST error is estimated.

Potentially, all inputs may introduce errors in the retrieved LST values. However, here, we only consider the radiometric noise, the uncertainty in surface emissivity, and errors in $W$ forecasts. The rectification of the satellite data from the real position to $0^{\circ}$ longitude may introduce errors in the determination of the SZA class. We have opted to ignore the impact of these errors on the overall LST error, taking into account the following: 1) The probability of having the wrong class of SZA for MSG is fairly low and very unlikely to be missed by more than one class, and 2) the extra GSW error induced by the wrong categorization of SZA by one class is negligible 


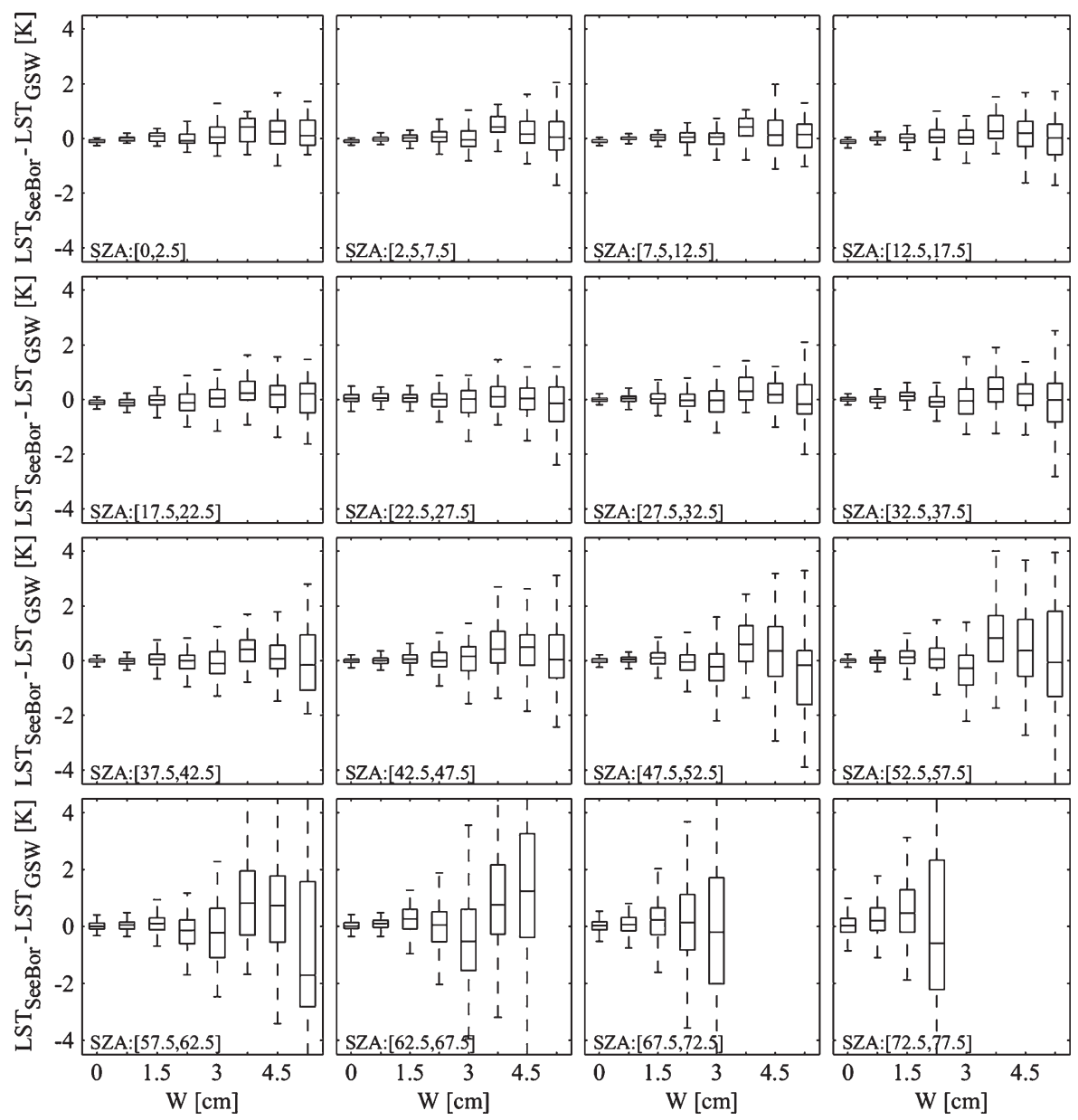

Fig. 3. Distribution of LST errors obtained for the GSW verification database, which are obtained for different classes of SZA (indicated in the bottom left of each panel) and water vapor content (W;x-axis in each diagram). The lines within each box plot correspond to the lower quartile, median, and upper quartile, respectively, while the whiskers extend to the remaining data.

for low SZA and generally lower than $0.8 \mathrm{~K}$ for high SZA (above $60^{\circ}$ ).

The misclassification of cloudy pixels as clear sky would have very high impact on the retrieved LST. According to validation results of the NWC SAF cloud mask for SEVIRI, the expected rate of missed clouds is on the order of 4\% [25]. These missed cases often correspond to broken clouds or cases in neighboring cloudy pixels. It is very difficult to propagate the uncertainty in cloud identification to LST error bars. Instead, LST retrievals over neighboring cloudy pixels are flagged.

\section{A. Framework}

Let us define the vector of model coefficients $\theta=$ $\left(A_{1}, A_{2}, A_{3}, B_{1}, B_{2}, B_{3}, C\right)$. Notice that the vector $\theta$ generated by the fitting process is a function of water content and view angle, i.e., $\theta=\theta(Y)$. Consider the LST estimator $L \hat{S} T=$ $f(\hat{X}, \hat{\theta})$ where $\hat{\theta}=\theta(\hat{Y})$ and $f(X, \theta)$ is the LST estimate given by model (3). A characterization of the model error is given by

$$
S_{\mathrm{LST}}=E\left[(f(\hat{X}, \hat{\theta})-L S T)^{2} \mid X, Y\right]^{1 / 2}
$$

where $E[\cdot \mid X, Y]$ stands for a mean value conditioned to $X$ and $Y$, i.e., for a given GSW input $X$ or $Y$, we want to compute the rmse of the LST estimate. By using the fact that $L S T=f(X, \theta)+\Delta L S T$ and assuming that $E[f(\hat{X}, \hat{\theta}) \mid X, Y]=f(X, \theta)$, we may write

$$
S_{\mathrm{LST}}^{2}=E\left[(f(\hat{X}, \hat{\theta})-f(X, \theta))^{2} \mid X, Y\right]+\Delta L S T^{2} .
$$

By taking a linear approximation of $f(\hat{X}, \hat{\theta})$ in the neighborhood of $(X, \theta)$ and denoting $\sigma_{X_{i}}^{2}=E\left[\left(\hat{X}_{i}-X_{i}\right)^{2} \mid X\right]$ and $\sigma_{\theta_{i}}^{2}=E\left[\left(\hat{\theta}_{i}-\theta_{i}\right)^{2} \mid Y\right]$, we are led to

$$
S_{\mathrm{LST}}^{2}=\sum_{i}\left(\frac{\partial f}{\partial X_{i}}\right)^{2} \sigma_{X_{i}}^{2}+\sum_{j}\left(\frac{\partial f}{\partial \theta_{j}}\right)^{2} \sigma_{\theta_{j}}^{2}+\Delta L S T^{2}
$$

where we have assumed that the components of $X$ and $Y$ are mutually independent and that $E\left[\left(\hat{X}_{i}-X_{i}\right) \mid X\right]=0$ and $E\left[\left(\hat{\theta}_{i}-\theta_{i}\right) \mid Y\right]=0$. Next, we study in detail the error due to each individual GSW input. 


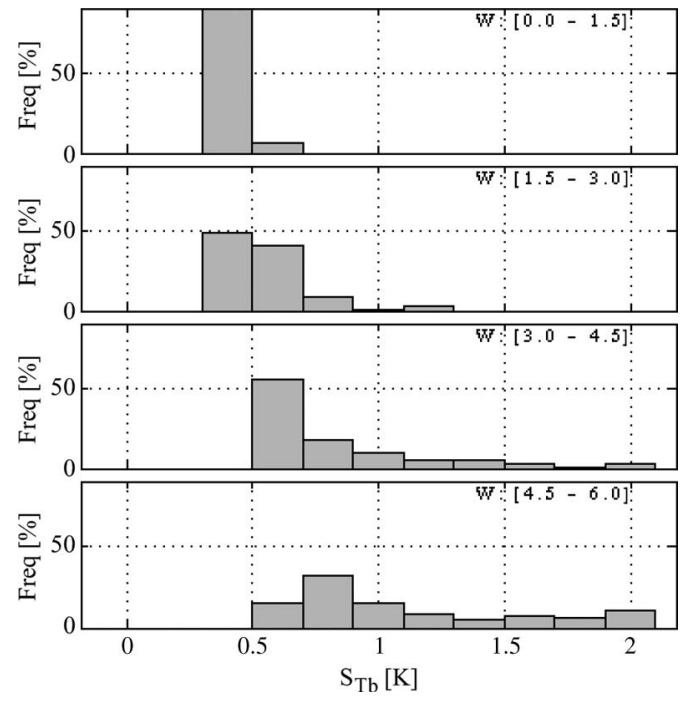

Fig. 4. Histograms of LST errors (in kelvins) attributed to the sensor noise, obtained for different classes of total column water vapor. From top to bottom: $0-1.5,1.5-3.0,3.0-4.5$, and $4.5-6.0 \mathrm{~cm}$.

\section{B. Impact of Sensor Noise}

The expected radiometric noise of SEVIRI channels IR108 and IR120 onboard MSG-2 is $\sigma_{T_{108}}=0.11 \mathrm{~K}$ and $\sigma_{T_{120}}=$ $0.16 \mathrm{~K}$, respectively. The associated LST uncertainty is then

$$
S_{T b}^{2}=S_{T b 108}^{2}+S_{T b 120}^{2}
$$

where

$$
S_{T b 108}^{2}=\left(\frac{\partial f}{\partial T_{108}}\right)^{2} \sigma_{T_{108}}^{2} \quad S_{T b 120}^{2}=\left(\frac{\partial f}{\partial T_{120}}\right)^{2} \sigma_{T_{120}}^{2} .
$$

Fig. 4 shows the distributions of errors attributed to the impact of sensor noise $S_{T b}$, grouping all possible SZA within different ranges of $W . S_{T b}$ is generally below $0.75 \mathrm{~K}$ and increases with the atmospheric water content. The larger variability within the moister atmospheres (bottom panel in Fig. 4) is largely associated to nonlinear effects on the atmospheric path for high SZA. In the most extreme cases, with $W$ higher than $3 \mathrm{~cm}, S_{T b}$ is higher than $0.5 \mathrm{~K}$ and may reach values above $2 \mathrm{~K}$.

\section{Impact of Uncertainties in Surface Emissivity}

The impact of uncertainties in surface emissivity for channels IR108 and IR120, $\sigma_{\varepsilon_{108}}$ and $\sigma_{\varepsilon_{120}}$, respectively, on LST is given by

$$
S_{\varepsilon}^{2}=S_{\varepsilon_{108}}^{2}+S_{\varepsilon_{120}}^{2}
$$

where

$$
S_{\varepsilon_{108}}^{2}=\left(\frac{\partial f}{\partial \varepsilon_{108}}\right)^{2} \sigma_{\varepsilon_{108}}^{2} \quad S_{\varepsilon_{120}}^{2}=\left(\frac{\partial f}{\partial \varepsilon_{120}}\right)^{2} \sigma_{\varepsilon_{120}}^{2} .
$$

Emissivity retrievals are based on the so-called vegetation cover method (VCM) [31], [32], where effective channel emis- sivity for any given pixel is estimated as a weighted average of channel emissivities of dominant bareground and vegetation types within the scene. Furthermore, it is considered that SEVIRI pixels may include a land $F_{\text {Land }}$ and an in-land water fraction $\left(1-F_{\text {Land }}\right)$, and thus, the effective pixel emissivity $\varepsilon_{\text {eff_IRn }}$ is given by

$$
\begin{aligned}
\varepsilon_{\mathrm{LAND}} \text { IRn } & =\varepsilon_{\mathrm{veg} \_\mathrm{IRn}} F V C+\varepsilon_{\mathrm{bg} \_\mathrm{IRn}}(1-F V C) \\
\varepsilon_{\text {eff_IRn }} & =\varepsilon_{\text {LAND_IRn }} F_{\text {Land }}+\varepsilon_{\text {WATER_IRn }}\left(1-F_{\text {Land }}\right)
\end{aligned}
$$

where $F V C$ is the pixel fraction of vegetation cover and $\varepsilon_{\text {veg_IRn }}, \varepsilon_{\text {bg_IRn }}$, and $\varepsilon_{\text {WATER_IRn }}$ are the vegetation, bareground, and water emissivities, respectively, for the splitwindow channel IRn. The values for $\varepsilon_{\text {veg_IRn }}$ and $\varepsilon_{\text {bg_IRn }}$ are available from lookup tables (Table II), determined for the land cover classes within the IGBP [21] database [32]. In the case of inland water, $\varepsilon_{\text {WATER_IRn }}$ is set to the Water Bodies values detailed in Table II. Channel emissivity is currently estimated from FVC retrieved by the Land-SAF from SEVIRI/Meteosat [33] and corresponds to five-day composites updated on a daily basis.

The uncertainties in retrieved emissivity are thoroughly discussed in [30]. These take into account inaccuracies in the VCM inputs (on the order of 0.1 for FVC; IGBP class dependent in the case of $\varepsilon_{\text {veg_IRn }}$ and $\left.\varepsilon_{\text {bg_IRn }}\right)$ and errors in the approximation made by (11), which ignores the effect of multiple reflections within the canopies/ground. A further source of emissivity errors relies on the classification of each SEVIRI pixel into one of the two categories: "land" with $F_{\text {Land }}=1$ or "water" with $F_{\text {Land }}=0$. To take this into account in the estimation of emissivity uncertainty, we assume an average error of 0.20 in $F_{\text {Land }}$; in coastal pixels, this uncertainty may reach 0.45 .

Error bars of channel emissivity, $\Delta \varepsilon_{108}$ and $\Delta \varepsilon_{120}$, are estimated operationally, along with the emissivity values themselves, and later used for LST error bars. Here, we assess the impact of emissivity uncertainties on LST, prescribing a fixed FVC characteristic of each IGBP land cover (Table II) and thus assigning to every profile in the SeeBor verification database a value of $\varepsilon_{108}, \varepsilon_{120}, \Delta \varepsilon_{108}$, and $\Delta \varepsilon_{120}$ (Table II). On top of this, we assume $F_{\text {Land }}$ to be equal to 0 or 1 , but prescribing an uncertainty of 0.2 , i.e., for "land" pixels, $F_{\text {Land }}$ may range from 0.8 to 1 , while for "water pixels," $F_{\text {Land }}$ lies between 0 and 0.20 . Fig. 5 shows the results obtained for different ranges of TCWV. As expected, the sensitivity to land surface emissivity is significantly higher for drier atmospheres, since under moist conditions, the impact of emissivity on the surface-emitted radiance is partially compensated by an opposite effect on the (higher) atmospheric radiation reflected by the surface [30]. Moreover, the higher values of $\Delta \varepsilon_{108}$ and $\Delta \varepsilon_{120}$ are often found in (semi-)arid regions (see Barren Sparsely Vegetated, Savanna, or Woody Savanna land cover types in Table II), leading to LST inaccuracies of $1 \mathrm{~K}$ or more under dry conditions ( $W$ below $1.5 \mathrm{~cm}$ ). In contrast, the impact on LST is always below $2 \mathrm{~K}$ for the moister atmospheres $(W>4.5 \mathrm{~cm})$. 
TABLE II

LAND SURFACE EMISSIVITY AND RESPECTIVE STANDARD DEVIATION FOR THERMAL WiNDOW CHANNELS ONBOARD SEVIRI-MSG, AND THE CORRESPONDENT FVC FOR EACH IGBP CLASS

\begin{tabular}{cccccc}
\hline IGBP Class & $\begin{array}{c}\mathrm{FVC} \\
(\Delta \mathrm{FVC}=0.1)\end{array}$ & $\varepsilon_{108}$ & $\Delta \varepsilon_{108}$ & $\varepsilon_{120}$ & $\Delta \varepsilon_{120}$ \\
\hline $\begin{array}{c}\text { Evergreen Forests } \\
\text { (needle- and broad-leaf) }\end{array}$ & 0.8 & 0.99136 & 0.00560 & 0.99248 & 0.00603 \\
\hline $\begin{array}{c}\text { Deciduous Forests } \\
\text { (needle- and broad-leaf) }\end{array}$ & 0.8 & 0.98776 & 0.00515 & 0.98840 & 0.00552 \\
\hline Mixed Forest & 0.8 & 0.98952 & 0.00537 & 0.99040 & 0.00577 \\
\hline Closed Shrublands & 0.8 & 0.98918 & 0.00684 & 0.99024 & 0.00617 \\
\hline Open Shrublands & 0.5 & 0.98120 & 0.00981 & 0.98355 & 0.00818 \\
\hline Woody Savannas & 0.5 & 0.97965 & 0.01105 & 0.98205 & 0.00948 \\
\hline Savannas & 0.5 & 0.97945 & 0.01086 & 0.98195 & 0.00936 \\
\hline Grasslands & 0.5 & 0.97930 & 0.01068 & 0.98185 & 0.00904 \\
\hline Permanent Wetlands & 0 & 0.99240 & 0.00260 & 0.99160 & 0.00610 \\
\hline Croplands & 0.5 & 0.98375 & 0.00606 & 0.98725 & 0.00762 \\
\hline Urban \& Built-Up & 0.1 & 0.96101 & 0.00959 & 0.97320 & 0.00652 \\
\hline Crop/Natural Veg. Mosaic & 0.5 & 0.98305 & 0.00592 & 0.98605 & 0.00738 \\
\hline Snow \& Ice & 0 & 0.98920 & 0.00650 & 0.96560 & 0.02410 \\
\hline Barren Sparsely Vegetated & 0.005 & 0.94802 & 0.02444 & 0.96603 & 0.01831 \\
\hline Water Bodies & 0 & 0.99000 & 0.00200 & 0.98560 & 0.00090 \\
\hline
\end{tabular}
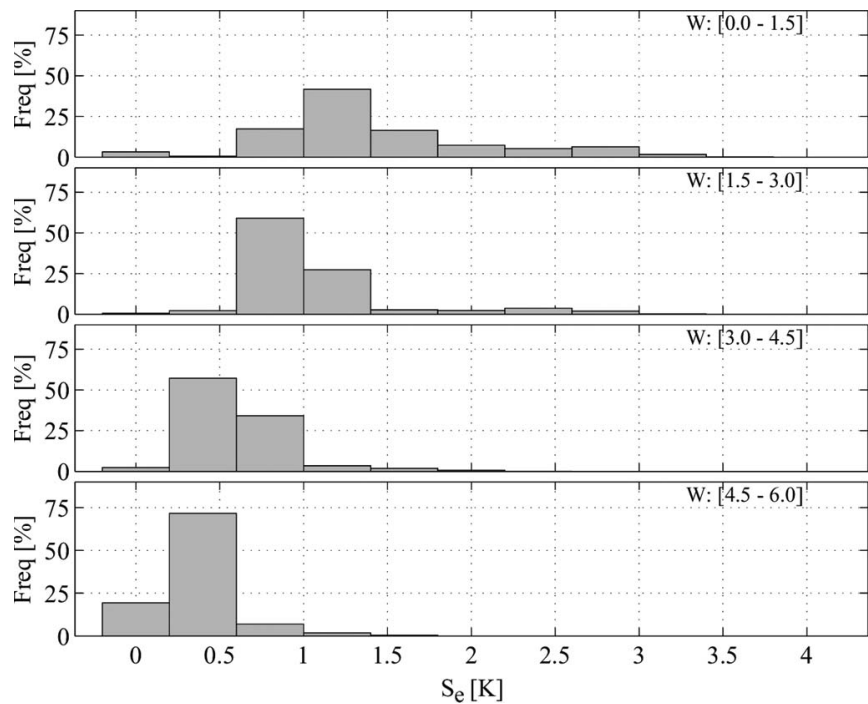

Fig. 5. As in Fig. 4, but for errors in LST (in kelvins) attributed to uncertainties in surface emissivity.

\section{Uncertainties in Forecasts of Atmospheric Water Vapor Content}

According to (6), the error due to uncertainties in the water vapor content is given by

$$
S_{W}^{2}=\sum_{j}\left(\frac{\partial f}{\partial \theta_{j}}\right)^{2} \sigma_{\theta_{j}}^{2}
$$

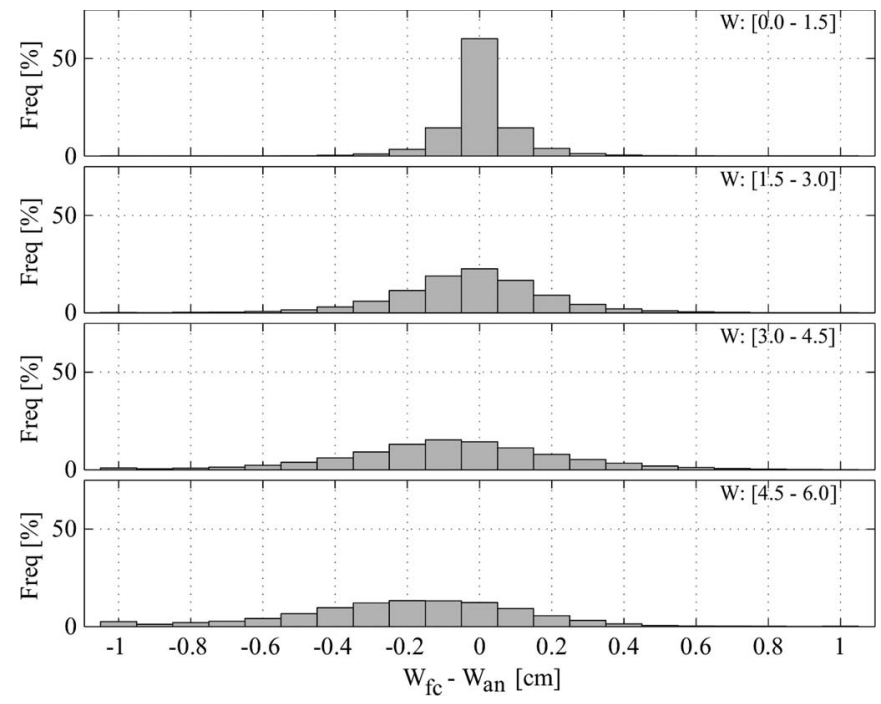

Fig. 6. Histograms of $W$ errors (in centimeters)—difference between forecasts and the respective analysis-for different classes of total column water vapor. From top to bottom: $0-1.5,1.5-3.0,3.0-4.5$, and $4.5-6.0 \mathrm{~cm}$.

where

$$
\sigma_{\theta_{j}}^{2}=E\left[\left(\hat{\theta}_{j}-\theta_{j}\right)^{2} \mid W, \Psi\right] .
$$

Since we neglect the uncertainty in the SZA $\Psi$, let us focus our attention on $W$. Given that $\hat{\theta}$ is a piecewise linear function, 

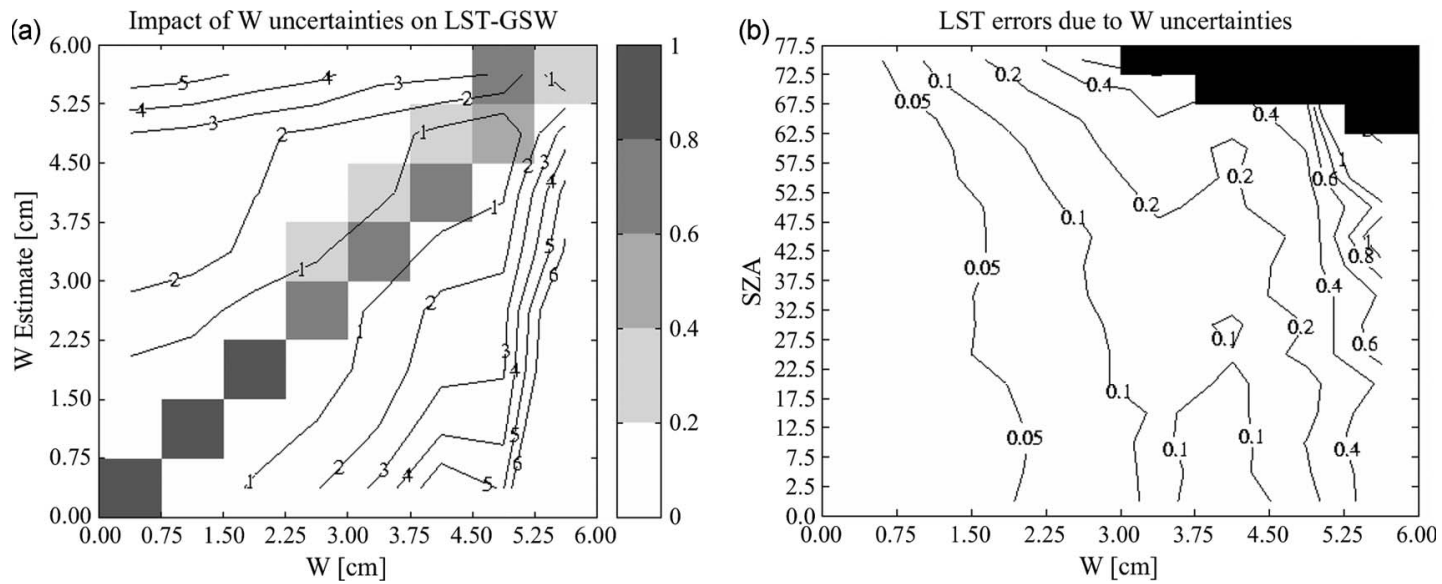

Fig. 7. (a) Probability (shaded boxes) of a reference value $W$ (horizontal axis) being forecast as $W_{\text {Estimate (vertical axis) and LST errors (contours, in kelvins) }}$ associated to $W$ forecast errors, for all possible SZAs up to $77.5^{\circ}$. (b) Contours of errors of LST retrievals obtained for all admissible classes of water vapor $(W)$ and SZA, taking into account the statistics of ECMWF forecast errors for $W$.

we have

$$
\begin{aligned}
\sigma_{\theta_{j}}^{2} & =E\left[\left(\hat{\theta}_{j}-\theta_{j}\right)^{2} \mid W\right] \\
& =\sum_{k}\left(\hat{\theta}_{j}\left(R_{k}\right)-\theta_{j}\right)^{2} P\left(\hat{W} \in R_{k} \mid W\right)
\end{aligned}
$$

where $R_{k}$ is the region of the water vapor domain where the $k$ th linear model is assumed. Therefore, the sets $R_{k}$ 's are a partition of the referred-to domain.

The operational estimation of LST with the GSW algorithm (3) applied to SEVIRI makes use of forecasts of TCWV $(W)$ provided by the European Centre for Medium-range Weather Forecasts (ECMWF) for parameter selection. To characterize $W$ error statistics, we compared ECMWF $W$ forecasts (with forecast steps ranging between 12 and $36 \mathrm{~h}$ ) with the respective analysis, for the 15th of each month during 2007. ECMWF grid points with model cloud cover higher than $10 \%$ were excluded. The histograms of the difference between forecasts and analyses are shown in Fig. 6, for different classes of TCWV. Forecast errors could also be assessed through a comparison with observations, e.g., radiosondes. However, here, we consider the model analysis to correspond to the best estimate of the state of the atmosphere at any given time. The recent evolution of assimilation techniques and assimilated data-including both conventional data such as radiosondes, and remote sensing - contributed to the significant improvement of ECMWF model analysis of water vapor content [34]. As a consequence, the bias of ECMWF humidity analysis has decreased significantly, supporting the use of analysis fields as reference for the estimation of forecast errors. Moreover, the procedure described here can also be easily reproduced whenever changes to the ECMWF model justify a reassessment of $W$ forecasts.

The comparison between $W$ forecasts and analysis (the reference value) allowed us to estimate the probability $P\left(\hat{W}_{i} \mid W_{j}\right)$, i.e., the probability that $\hat{W}$ belongs to the water vapor content class $W_{i}$, given that the true class is $W_{j}$. This probability is then used to compute the expected LST error, according to (12)-(14). Fig. 7(a) shows shaded values of $P(\hat{W} \mid W)$ superimposed on contours of LST errors associated to $\hat{W}$

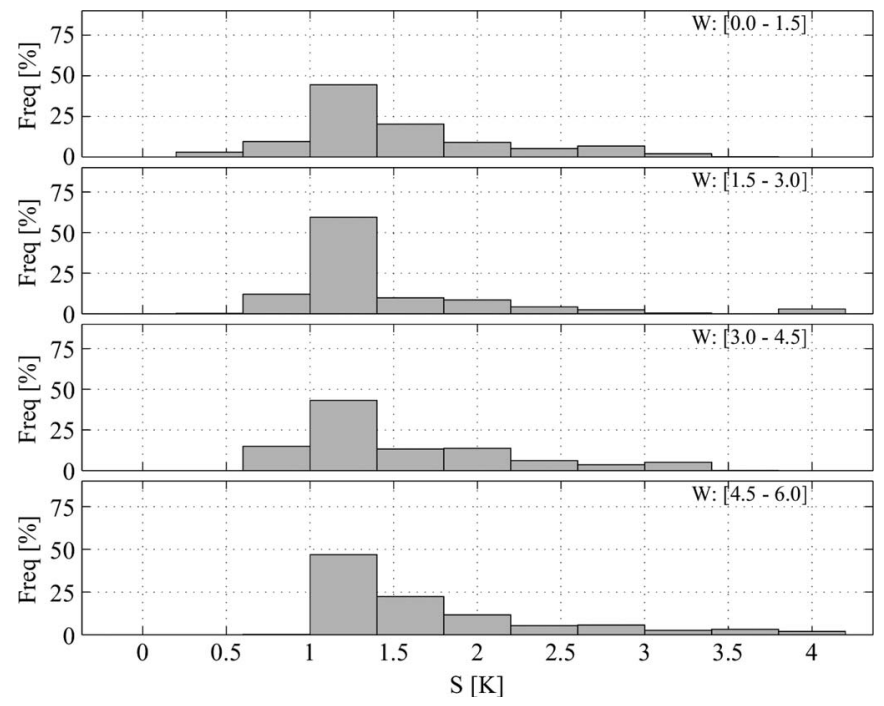

Fig. 8. Histograms of LST uncertainties (in kelvins), including all sources of errors grouped by $W$.

forecast errors, i.e., to the wrong choice of GSW parameters. The estimated errors of LST retrievals associated to TCWV uncertainties, which are obtained through the application of (12)-(14) to all possible classes of $W$ and SZA, are shown in Fig. 7(b). These are generally below $0.2 \mathrm{~K}$ for dry to moderately moist atmospheres. Higher values occur only for $W$ above $5.25 \mathrm{~cm}$.

\section{E. Uncertainty of LST Retrievals}

The estimation of LST error bars $S_{\mathrm{LST}}$ assumes that all sources of errors described in the previous sections are independent

$$
S_{\mathrm{LST}}=\sqrt{S_{T b}^{2}+S_{\varepsilon}^{2}+S_{W}^{2}+\Delta L S T^{2}} .
$$

Fig. 8 shows histograms of LST uncertainties for four nonoverlapping ranges of $W$. These were obtained for "LST retrievals" computed for the verification data set described in Section II-B and taking into account the uncertainties of the different input variables, as discussed earlier. Dry atmospheres 


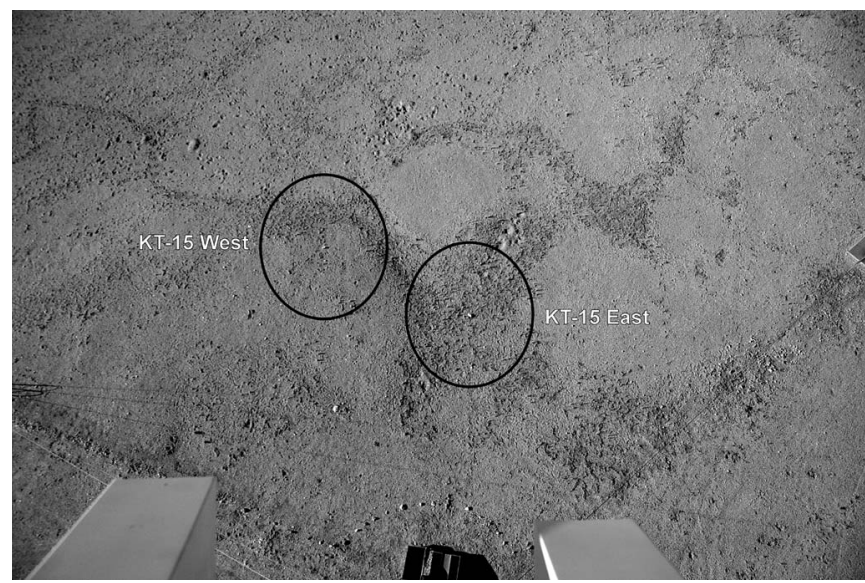

Fig. 9. Field of view of the two downlooking KT15.85 IIP radiometers, on the gravel plain north of Gobabeb LST validation station (KT-15 West and KT-15 East). The ellipses cover about $13 \mathrm{~m}^{2}$ (horizontal diameter about $3.7 \mathrm{~m}$ ).

present the widest range of $S_{\mathrm{LST}}$. In such conditions, the total error depends essentially on emissivity uncertainties and to a lesser extent on the view zenith angle. Nevertheless, $S_{\mathrm{LST}}$ distributions tend to be shifted to the right with total water vapor content, i.e., LST error bars increase for higher optical depths.

\section{COMPARISON OF SEVIRI/METEOSAT RETRIEVALS WiTH IN SITU OBSERVATIONS}

The GWS algorithm described in Section III is used by the Land-SAF to generate LST from SEVIRI/Meteosat measurements on an operational basis. LSTs are then freely available (http://landsaf.meteo.pt), along with an estimated uncertainty based on the error propagation analysis described in Section IV. Ultimately, also independent ground measurements are needed to validate remotely sensed LSTs. As discussed in [11] and [24], ground measurements have their own issues, including, among others, the following: 1) the low number and discontinuity of high-quality data sets; 2) the lack of global representativeness; and 3) the upscaling of LST "point" measurements to satellite pixel size. Here, we compare satellitederived LSTs with in situ observations collected at a permanent validation station at Gobabeb, Namibia $\left(23^{\circ} 33^{\prime} \mathrm{S}\right.$ and $\left.15^{\circ} 03^{\prime} \mathrm{E}\right)$. For thermally heterogeneous land surfaces, point 3 ) introduces uncertainties that are not easily quantified; Gobabeb validation station was chosen because it is located in a relatively homogeneous area characterized by large gravel plains, which greatly simplifies the upscaling. The station is equipped with self-calibrating chopped KT15.85 IIP radiometers (Heitronics), which are sensitive to radiance between 9.6 and $11.5 \mu \mathrm{m}$ and have an absolute accuracy of about $0.6 \mathrm{~K}$. Two KT15.85 IIP radiometers are mounted at $25-\mathrm{m}$ height and observe neighboring surface areas of about $13 \mathrm{~m}^{2}$ each under a view angle of $30^{\circ}$ in direction north (Fig. 9). A third KT15.85 IIP measures downwelling long-wave radiance at $52^{\circ}$ zenith angle. In situ LST is calculated as the average of the measurements taken by the downward-looking radiometers, previously corrected for surface emissivity (taken to be 0.959 as representative of gravel plains [30]) and reflected downwelling radiance (further details in [24]).
Comparisons between Gobabeb LST and LST obtained for the nearest SEVIRI/MSG pixel north of the station (i.e., exclusively located in the gravel plain) were performed for the period from May 2008 to March 2009. Fig. 10 shows scatter plots of in situ versus satellite LST retrievals for six representative months. Overall, there is good agreement between the two data sets, with root-mean-square (rms) differences between $1{ }^{\circ} \mathrm{C}$ and $2{ }^{\circ} \mathrm{C}$. The high cloud cover during the rainy season significantly reduces the number of retrieved LST values, explaining the fewer data points in the July 2008 plot (Fig. 10, upper right panel). The higher discrepancies between the two data sets generally occur when SEVIRI/MSG LST is lower than the corresponding station LST (e.g., the data points substantially above the 1:1 line in January 2009). These are likely to be caused by cloud contamination or cloud shadows within the MSG pixel and thus also related to the different spatial scales of the in situ "point" measurements and the satellite measurements. The monthly average error estimated for SEVIRI/MSG LST lies between $2{ }^{\circ} \mathrm{C}$ and $3{ }^{\circ} \mathrm{C}$, which is larger than the rms differences between the in situ and the satellite measurements. The area surrounding Gobabeb is dominated by bareground gravel plains, which are associated with relatively large emissivity uncertainties. Under the arid conditions prevalent at Gobabeb, these uncertainties constitute the major source of error for LST satellite estimates (see Fig. 5).

\section{Discussion AND CONCLUding REMARKS}

The GSW algorithm is a semiempirical algorithm that allows the estimation of LST from TOA brightness temperatures of two adjacent channels within the atmospheric window part of the spectrum, assuming that the channel surface emissivities are known. A version of the GSW was trained for the series of MSG satellites and is currently used for operational retrievals of LST by the Land-SAF. To maximize the algorithm performance over a wide range of conditions, the GSW parameters are tuned for classes of satellite view angle and TCWV [14].

A reliable estimation of the uncertainty of remote sensing retrievals is often essential for the optimal use of the retrieved variable. This paper focuses on the quantification of error bars associated to LST estimations from SEVIRI/MSG through a careful characterization of the following: 1) the uncertainty of the GSW algorithm itself, which is highly dependent on the retrieval conditions-view angle and atmospheric water vapor content, and 2) the uncertainty of the input variables and their propagation through the GSW algorithm. For the latter, we take into account the expected sensor noise for the SEVIRI window channels onboard the MSG series, the error bars of surface emissivity retrievals (discussed in [30]), and forecast errors of TCWV $(W)$. Since the GSW is applicable to clear-sky pixels only, the misclassification of a (partially) cloud-covered scene would lead to erroneous LST values. The resulting error is difficult to estimate a priori, as it depends on, for example, the extent of the cloud cover or cloud top height. Considering that the overall performance of the cloud mask used is fairly good [25], the LST error bars do not take into account the uncertainty of the pixel classification, but instead, the cloud mask confidence is made available to the user through the LST quality flag. 

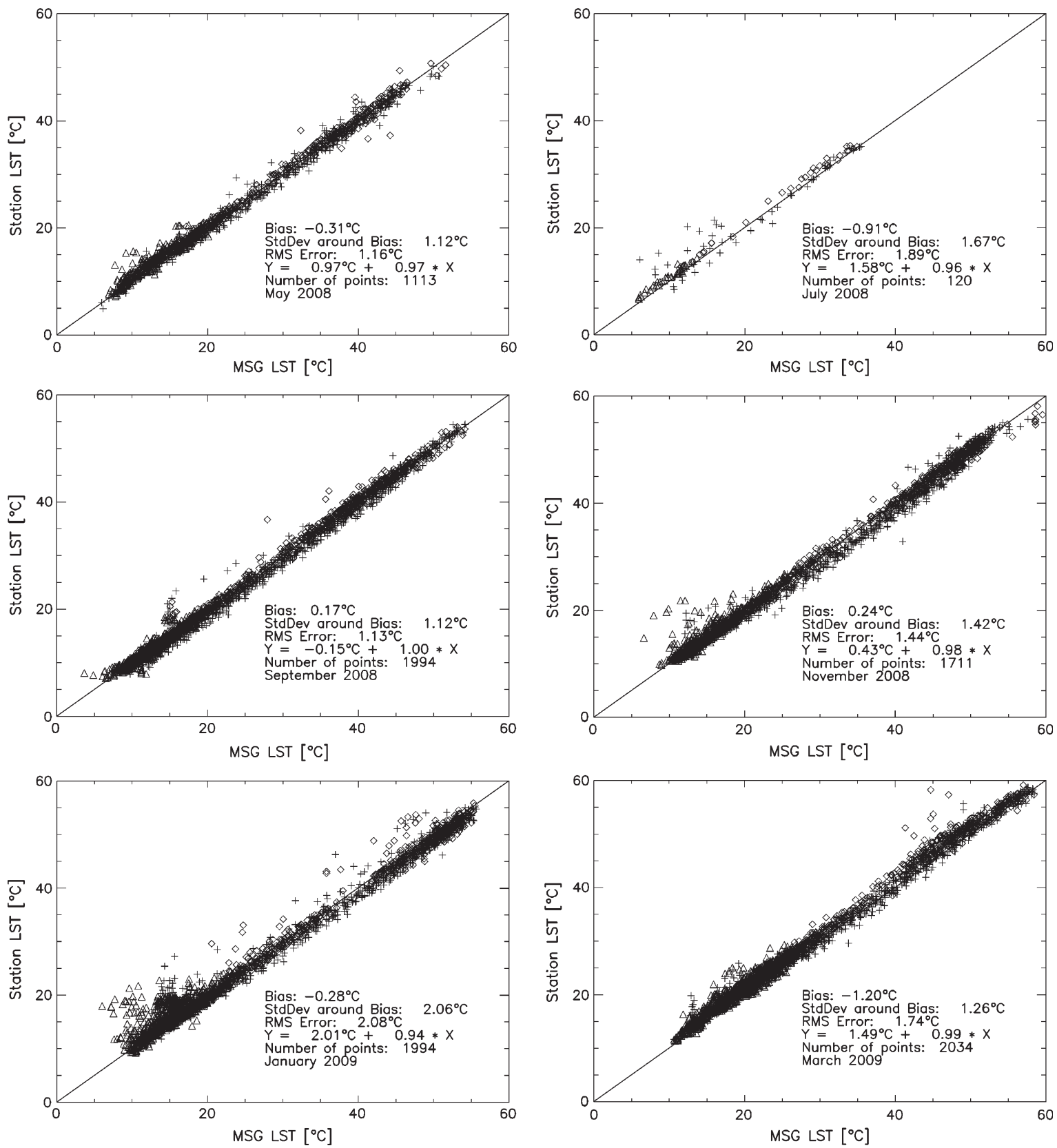

Fig. 10. Scatter plots of LST (in degree Celsius) measurements at Gobabeb validation station ( $y$-axis) versus corresponding SEVIRI/MSG LST retrievals $(x$-axis) taken over a seasonal cycle; the 1:1 line is shown for reference. Each panel indicates the mean difference between satellite retrievals and in situ observations (bias), the standard deviation around the bias, the rms difference, the linear regression equation, the number of available points, and month and year. Crosses, diamonds, and triangles represent data in the morning, afternoon, and evening, respectively.

Satellite zenith view angle (SZA) and $W$ are implicit input variables for LST retrievals, in the sense that their values are used to determine the best set of GSW parameters $\left[A_{i}, B_{i}\right.$, and $C$ in (3)]. The uncertainty of $\sim 1 / 3$ pixel in the geolocation of level 1.5 SEVIRI data has a marginal effect on LST error bars, since only pixels with SZA close to the upper/lower limits may risk being misclassified to a neighboring SZA class. The probability of choosing inappropriate GSW parameters due to a misclassification of $W$ is estimated from error statistics of humidity forecasts of the current version of ECMWF model; the procedure described in this paper can easily be duplicated for future model releases. Such probability is then combined with the results of a sensitivity analysis of the GSW to estimate their contribution to LST error bars.
LST retrievals representative for a seasonal cycle are compared with in situ measurements taken at Gobabeb validation station (Namibia), which is part of Land-SAF's validation effort. The permanent validation station is located within an arid region characterized by vast gravel plains. SEVIRI and in situ LST are found to be in good agreement with rms differences of $2{ }^{\circ} \mathrm{C}$ or less, which is within the estimated error for SEVIRI LST. Such validation results provide further confidence in the retrieval algorithm and error bar estimations.

The spatial coverage of LST retrievals from SEVIRI/MSG data presented here is then essentially based on the respective uncertainty, in contrast with most (split-window) algorithms for LST, where estimations are restricted to SZA below a fixed threshold (often $\sim 60^{\circ}$; see, e.g., [14] and [15]). 

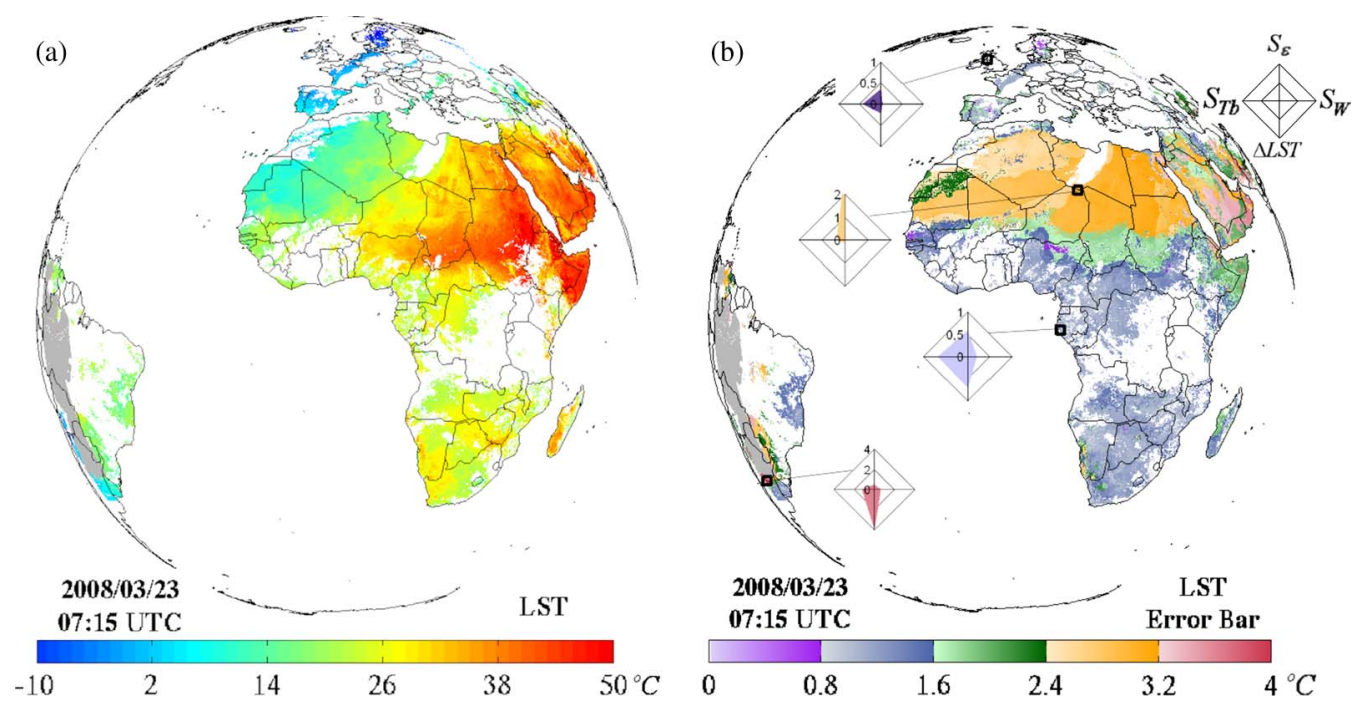

Fig. 11. (a) LST (in degree Celsius) retrievals for the 7:15 UTC time slot of the March 23, 2008 and (b) respective error bars (in degree Celsius); the diamonds show the relative contribution of ("north") uncertainty in emissivity, ("east") water vapor content, ("west") sensor noise, and ("south") uncertainty in the GSW associated with specific retrieval conditions.

Within the MSG disk, the atmosphere is often fairly dry for clear-sky conditions and for relatively large $\left(\sim 60^{\circ}-70^{\circ}\right)$ SZA, partially compensating for the poorer performance of the GSW algorithm due to the long optical path. Fig. 11 shows one such example, where parts of Northern Europe, the Middle East, and Saudi Arabia, which are cloud free, present a relatively low atmospheric water vapor content, which allows the estimation of LST with a reasonable degree of accuracy. The far west region of Southern America is also viewed at relatively high angles as the aforementioned areas but presents a much higher atmospheric humidity, which would lead to meaningless retrievals of LST. Thus, the analysis of the various error sources of remotely sensed LST allows the maximization of the product spatial coverage. In the case of LST provided by the Land-SAF, the fields are distributed along with realistic estimations of the respective error bars on a pixel-by-pixel basis, allowing users to make the ultimate decision on the applicability of the retrieved product.

\section{ACKNOWLEDGMENT}

This work was carried out within the context of the LandSAF project, funded by the European Organization for the Exploitation of Meteorological Satellites.

\section{REFERENCES}

[1] J. Schmetz, P. Pili, S. Tjemkes, D. Just, J. Kerkman, S. Rota, and A. Ratier, "An introduction to Meteosat Second Generation (MSG)," Bull. Amer. Meteorol. Soc., vol. 83, no. 7, pp. 977-992, Jul. 2002.

[2] I. F. Trigo and P. Viterbo, "Clear-sky window channel radiances: A comparison between observations and the ECMWF model," J. Appl. Meteorol., vol. 42, no. 10, pp. 1463-1479, Oct. 2003.

[3] K. E. Mitchell, D. Lohmann, P. R. Houser, E. F. Wood, J. C. Schaake, A. Robock, B. A. Cosgrove, J. Sheffield, Q. Duan, L. Luo, R. W. Higgins, R. T. Pinker, J. D. Tarpley, D. P. Lettenmaier, C. H. Marshall, J. K. Entin, M. Pan, W. Shi, V. Koren, J. Meng, B. H. Ramsay, and A. A. Bailey, "The multi-institution North American Land Data Assimilation System (NLDAS): Utilizing multiple GCIP products and partners in a continental distributed hydrological modeling system," J. Geophys. Res., vol. 109, no. D7, p. D07 S90, 2004. DOI: 10.1029/2003JD003823.

[4] F. Caparrini, F. Castelli, and D. Entekhabi, "Variational estimation of soil and vegetation turbulent transfer and heat flux parameters from sequences of multisensor imagery," Water Resour. Res., vol. 40, no. 12, p. W12515, Dec. 2004. DOI:10.1029/2004WR003358.

[5] J. Qin, S. Liang, R. Liu, H. Zhang, and B. Hu, "A weak-constraint-based data assimilation scheme for estimating surface turbulent fluxes," IEEE Geosci. Remote Sens. Lett., vol. 4, no. 4, pp. 649-653, Oct. 2007.

[6] M. G. Bosilovich, J. D. Radakovich, A. da Silva, R. Todling, and F. Verter, "Skin temperature analysis and bias correction in a coupled land-atmosphere data assimilation system," J. Meteorol. Soc. Jpn., vol. 85A, pp. 205-228, 2007.

[7] W. P. Kustas and J. M. Norman, "Use of remote sensing for evapotranspiration monitoring over land surfaces," Hydrol. Sci. J., vol. 41, no. 4, pp. 495-515, 1996.

[8] Z. Wan, P. Wang, and X. Li, "Using MODIS land surface temperature and Normalized Difference Vegetation Index products for monitoring drought in the southern Great Plains, USA," Int. J. Remote Sens., vol. 25, no. 1, pp. 61-72, Jan. 2004.

[9] M. Jin, "Analysis of land skin temperature using AVHRR observations," Bull. Amer. Meteorol. Soc., vol. 85, no. 4, pp. 587-600, Apr. 2004.

[10] M. Jin, R. E. Dickinson, and D. Zhang, "The footprint of urban areas on global climate as characterized by MODIS," J. Clim., vol. 18, no. 10, pp. 1551-1565, May 2005.

[11] Y. Yu, J. L. Privette, and A. C. Pinheiro, "Evaluation of split-window land surface temperature algorithms for generating climate data records," IEEE Trans. Geosci. Remote Sens., vol. 46, no. 1, pp. 179-192, Jan. 2008.

[12] P. Dash, F. M. Göttsche, F. S. Olesen, and H. Fischer, "Land surface temperature and emissivity estimation from passive sensor data: Theory and practice-current trends," Int. J. Remote Sens., vol. 23, no. 13, pp. 2563 2594, Jul. 2002.

[13] A. J. Prata, "Land surface temperature derived from the Advanced Very High Resolution Radiometer and the Along-track Scanning Radiometer: 1. Theory," J. Geophys. Res., vol. 98, no. D9, pp. 16689-16702, 1993.

[14] Z. Wan and J. Dozier, "A generalized split-window algorithm for retrieving land surface temperature from space," IEEE Trans. Geosci. Remote Sens., vol. 34, no. 4, pp. 892-905, Jul. 1996.

[15] D. Sun and R. T. Pinker, "Estimation of land surface temperature from a Geostationary Operational Environmental Satellite (GOES-8)," J. Geophys. Res., vol. 108, no. D11, p. 4326, 2003. DOI: 10.1029/ 2002JD002422.

[16] P. Schmetz, P. Pili, S. Tjemkes, D. Just, J. Kerkman, S. Rota, and A. Ratier, "Radiometric performance of SEVIRI," Bull. Amer. Meteorol. Soc., vol. 83, no. 7, pp. ES50-ES51, 2002.

[17] E. Borbas, S. W. Seemann, H.-L. Huang, J. Li, and W. P. Menzel, "Global profile training database for satellite regression retrievals with estimates of skin temperature and emissivity," in Proc. Int. ATOVS Study Conf.-XIV, Beijing, China, May 25-31, 2005, pp. 763-770. 
[18] S. W. Seemann, J. Li, W. P. Menzel, and L. E. Gumley, "Operational retrieval of atmospheric temperature, moisture, and ozone from MODIS infrared radiances," J. Appl. Meteorol., vol. 42, no. 8, pp. 1072-1091, Aug. 2003.

[19] F. Chevallier, "Sampled databases of 60-level atmospheric profiles from the ECMWF analyses," ECMWF, Reading, U.K., NWP SAF Res. Rep. 4, Jan. 2002.

[20] A. Chedin, N. A. Scott, C. Wahiche, and P. Moulinier, "The improved initialization inversion method: A high resolution physical method for temperature retrievals from satellites of the TIROS-N series," J. Appl. Meteorol., vol. 24, no. 2, pp. 128-143, Feb. 1985.

[21] A. S. Belward, "The IGBP-DIS global $1 \mathrm{~km}$ land cover data set (DISCover)-Proposal and implementation plans," IGBP-DIS Office, Toulouse, France, 1996. IGBP-DIS working paper 13.

[22] A. Berk, G. P. Anderson, P. K. Acharya, J. H. Chetwynd, L. S. Bernstein, E. P. Shettle, M. W. Matthew, and S. M. Alder-Golden, MODTRAN4 Version 2 User's Manual. Hanscom AFB, MA: Air Force Res. Lab., Space Vehicles Directorate, Air Force Mater. Command, 2000.

[23] J. Schmetz, P. Pili, S. Tjemkes, D. Just, J. Kerkman, S. Rota, and A. Ratier, "SEVIRI calibration," Bull. Amer. Meteorol. Soc., vol. 83, no. 7, pp. ES52-ES53, 2002.

[24] I. F. Trigo, I. T. Monteiro, F. Olesen, and E. Kabsch, "An assessment of remotely sensed land surface temperature," J. Geophys. Res., vol. 113, no. D17, p. D17 108, Sep. 2008. DOI:10.1029/2008JD010035.

[25] NWC-SAF, Algorithm Theoretical Basis Document for 'Cloud Products', Nov. 7, 2007. (CMa-PGE01, CT-PGE02 \& CTTH-PGE03 v1.4). SAF/ NWC/CDOP/MFL/SCI/ATBD/01, Issue 1, Rev. 4. [Online]. Available: http://nwcsaf.inm.es/

[26] D. A. Faysash and E. A. Smith, "Simultaneous land surface temperatureemissivity retrieval in the infrared split window," J. Atmos. Ocean. Technol., vol. 16, no. 11, pp. 1673-1689, Nov. 1999.

[27] C. D. Rodgers, Inverse Methods for Atmospheric Sounding: Theory and Practice, ser. Series on Atmospheric, Ocean and Planetary Physics, vol. 2. Hackensack, NJ: World Scientific, 2000.

[28] D. Sun and R. T. Pinker, "Retrieval of surface temperature from the MSGSEVIRI observations: Part I. Methodology," Int. J. Remote Sens., vol. 28, no. 23 , pp. 5255-5272, Jan. 2007.

[29] R. T. Pinker, D. Sun, M. Miller, and G. J. Robinson, "Diurnal cycle of land surface temperature in a desert encroachment zone as observed from satellites," Geophys. Res. Lett., vol. 34, no. 11, p. L11 809, Jun. 2007. DOI:10.1029/2007GL03186.

[30] I. F. Trigo, L. F. Peres, C. C. DaCamara, and S. C. Freitas, "Thermal land surface emissivity retrieved from SEVIRI/Meteosat," IEEE Trans. Geosci. Remote Sens., vol. 46, no. 2, pp. 307-315, Feb. 2008.

[31] V. Caselles and J. A. Sobrino, "Determination of frosts in orange groves from NOAA-9 AVHRR data," Remote Sens. Environ., vol. 29, no. 2, pp. 135-146, Aug. 1989.

[32] L. F. Peres and C. C. DaCamara, "Emissivity maps to retrieve land-surface temperature from MSG/SEVIRI," IEEE Trans. Geosci. Remote Sens., vol. 43, no. 8, pp. 1834-1844, Aug. 2005.

[33] F. J. Garcia-Haro, S. Sommer, and T. Kemper, "Variable multiple endmember spectral mixture analysis (VMESMA)," Int. J. Remote Sens., vol. 26, no. 10, pp. 2135-2162, May 2005.

[34] E. Andersson, P. Bauer, A. Beljaars, F. Chevallier, E. Hólm, M. Janisková, P. Kållberg, G. Kelly, P. Lopez, A. McNally, E. Moreau, A. J. Simmons, J.-N. Thépaut, and A. M. Tompkins, "Assimilation and modeling of the atmospheric hydrological cycle in the ECMWF forecasting system," Bull. Amer. Meteorol. Soc., vol. 86, no. 3, pp. 387-402, Mar. 2005.

[35] T. J. Hewison and M. König, "Inter-calibration of Meteosat imagers and IASI," in Proc. EUMETSAT Meteorol. Satellite Conf., Darmstadt, Germany, Sep. 8-12, 2008.

[36] G.-M. Jiang and Z.-L. Li, "Split-window algorithm for land surface temperature estimation from MSG1-SEVIRI data," Int. J. Remote Sens., vol. 29, no. 20, pp. 6067-6074, Oct. 2008.

[37] J. C. Jiménez-Muñoz and J. A. Sobrino, "Error sources on the land surface temperature retrieved from thermal infrared single channel remote sensing data," Int. J. Remote Sens., vol. 27, no. 5, pp. 999-1014, Mar. 2006.

[38] J. A. Sobrino and M. Romaguera, "Land surface temperature retrieval from MSG1-SEVIRI data," Remote Sens. Environ., vol. 92, no. 2, pp. 247-254, Aug. 2004.

[39] C. Coll, V. Caselles, J. M. Galve, E. Valor, R. Niclós, and J. M. Sánchez, "Evaluation of split-window and dual-angle correction methods for land surface temperature retrieval from Envisat/Advanced Along, Track Scanning Radiometer (AATSR) data," J. Geophys. Res., vol. 111, no. D12, p. D12 105, Jun. 2006. DOI:10.1029/2005JD006830.

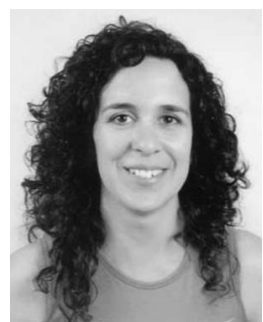

Sandra C. Freitas received the B.S. degree in geophysical sciences from the University of Lisbon, Lisbon, Portugal, in 1999 and the M.S. degree in geographical information systems from the Technical University of Lisbon, Lisbon, in 2006.

Since 2000, she has been with the Instituto de Meteorologia, Lisbon, working for the Satellite Application Facility on Land Surface Analysis (Land$\mathrm{SAF}$ ), funded by the European Organization for the Exploitation of Meteorological Satellites. She has been working in the development and maintenance of the Land-SAF land surface temperature product as well as on software applications for Land-SAF users.

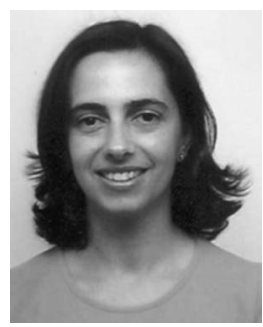

Isabel F. Trigo received the B.S. and M.S. degrees in geophysical sciences from the University of Lisbon, Lisbon, Portugal, in 1993 and 1997, respectively, and the Ph.D. degree in climatology from the University of East Anglia, Norfolk, U.K., in 2000.

In 2001, she began her collaboration with the Satellite Application Facility on Land Surface Analysis (Land-SAF), part of the European Organization for the Exploitation of Meteorological Satellites (EUMETSAT) Ground Segment, as a Visiting Scientist at the European Centre for Medium-range Weather Forecasts. She continued to work for the Land-SAF at the Instituto de Meteorologia, Lisbon. She is also currently with the Instituto Dom Luiz, Lisboa. Her research is focused on the retrieval of biogeophysical parameters over land, particularly on applications of EUMETSAT satellites- the geostationary series and the recent polar orbiter, MetOp. Currently she is the Scientific Coordinator of the Land-SAF.

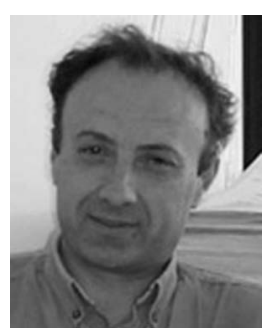

José M. Bioucas-Dias (S'87-M'95) received the E.E., M.Sc., Ph.D., and Agregado degrees in electrical and computer engineering from the Instituto Superior Técnico (IST), Engineering School, Technical University of Lisbon, Lisbon, Portugal, in 1985, 1991, 1995, and 2007, respectively.

Since 1995, he has been with the Department of Electrical and Computer Engineering, IST. He is also a Senior Researcher with the Communication Theory and Pattern Recognition Group of the Institute of Telecommunications. He is a Researcher of several national and international research projects and networks, including the Marie Curie Actions "Hyperspectral Imaging Network (HYPER-I-NET)" and the "European Doctoral Program in Signal Processing (SIGNAL)." His scientific interests include signal and image processing, pattern recognition, optimization, and remote sensing.

Dr. Bioucas-Dias was an Associate Editor of the IEEE TRANSACTION ON CIRCUITS AND SYSTEMS II. He has been a member of program committees of several international conferences, including CVPR, IGARSS, ICIP, SPIE, EMMCVPR, ISVC, and WHISPERS.

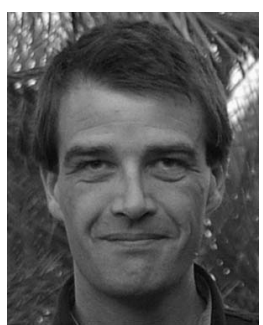

Frank-M. Göttsche received the M.Sc. degree in physics and the Ph.D. degree in geophysics from the University of Kiel, Kiel, Germany, in 1993 and 1997, respectively.

He then worked until 2003 as a Research Scientist with the Institute of Meteorology and Climate Research (IMK), Forschungszentrum Karlsruhe, Karlsruhe, Germany. Between 2003 and 2007, he was an Assistant Professor with the Physics Department, United Arab Emirates University, Al-Ain, UAE, and served as a Scientific Consultant with the Satellite Application Facility on Land Surface Analysis (Land-SAF). Since 2007, he has been a Project Scientist for Land-SAF at the IMK, where he is in charge of permanent ground truth stations in Europe and Africa and performs research in the field of LST upscaling and validation. His main areas of research were the retrieval of land surface temperature from satellite data with methods from artificial intelligence and the modeling of the diurnal temperature cycle. 